\title{
FOOD FOR THOUGHT
}

\section{How Food and Economics Intersect in Rural Ecuador}

LINDSAY STONE

DIETARY TRENDS CAN HAVE LARGE IMPLICATIONS ON PUBLIC HEALTH. THERE IS A STRONG PHYSIOLOGICAL CONNECTION BETWEEN FOOD CONSUMPTION AND ONE'S WELL-BEING. THUS NUTRITION IS AN IMPORTANT FACTOR IN A NATION'S OVERALL HEALTH. MANY FACTORS CONTRIBUTE TO HOW AND WHY AN INDIVIDUAL EATS CERTAIN FOODS. IN ECUADOR, HISTORICAL, SOCIOECONOMIC, CULTURAL, BEHAVIORAL, AND ENVIRONMENTAL FACTORS INFLUENCE THE DIFFERENT DIETS, AND THEREBY, THE NUTRITIONAL CONDITIONS, OF DIFFERENT ETHNIC, AND REGIONAL GEOGRAPHIC POPULATIONS. DISCREPANCIES AMONG THESE GROUPS ARE PARTICULARLY NOTICEABLE IN SIERRA, ECUADOR'S THE HIGHLAND REGION. THIS PAPER EXAMINES THE PREVALENCE OF MALNUTRITION ACROSS ECUADOR. SPECIFICALLY, IT CONSIDERS HOW THE ECUADORIAN DIET TOOK SHAPE, AND HOW DIFFERENT SUB-CUISINES CONTRIBUTE TO MALNUTRITION. WHILE ALL REGIONS ARE CONSIDERED, A FOCUS IS PLACED PRIMARILY ON THE SIERRA, GIVEN THAT LEVELS OF MALNUTRITION ARE NOTICEABLY HIGHER IN THIS REGION, AND THAT THIS HIGHLAND AREA IS HOME TO LARGE RURAL AND INDIGENOUS COMMUNITIES WHO ARE MOST SIGNIFICANTLY IMPACTED BY THE AREA'S NUTRITIONAL CONDITIONS. 
Fried plantains, steamed tubers, spice-rubbed beef, empanadas, sipping chocolate, flour tortillas... such is just a sampling of the variety of foods and meals that can be found across the different geographical regions of Ecuador. This Latin American country spans from the Galapagos Islands and the country's Pacific coast to the Amazon jungle and is split down the middle by the Andes Mountain Range. Ecuador's four regions - the Galapagos Islands, the Costa, the Sierra, and Amazonia - are home to several different ethnic groups; (i.e., including people from Amerindian lineages, such as the Quechua who descend from the Inca Empire), Afro-Ecuadorians (i.e., descendants of African slaves, such as those commonly imported during the time of Spanish colonization), and Mestizo-Ecuadorians (i.e., those of mixed European and Amerindian ancestry). Over the centuries, the different cultural groups across Ecuador have adopted various food habits and diets due to their respective histories and geographical locations.

Through food's "consumption... and the social and cultural processes it sustains," what one eats "[contributes] to the creation of collective identities" (Schlüter 9I, 9I). It is not surprising to find that "food is a very important aspect of the ethnic identity" for many in this Latin American country (Camacho 158). A diversity of diets and cuisines can be found across Ecuador, which vary according to altitude, cultural heritage, and other "ecological and socioeconomic factors" (Camacho ${ }^{15} 6$ ). In this way, different eating patterns contain characteristic elements

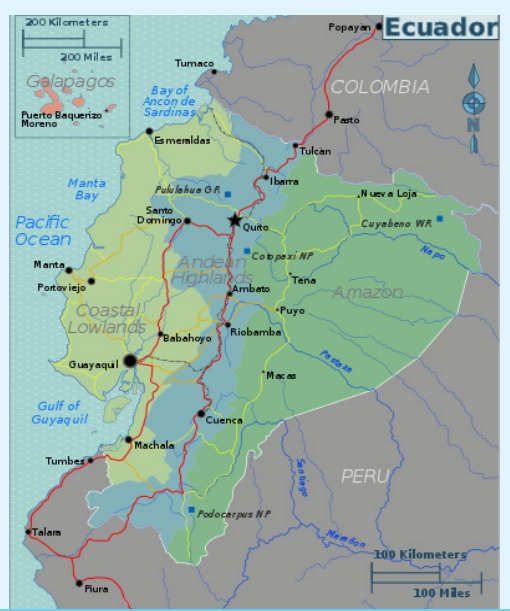

FIGURE 1: A MAP OF THE DIFFERENT REGIONS OF ECUADOR (COURTESY OF WIKIMEDIA COMMONS) that distinguish a given dish or food item as belonging to specific categories; foods can be distinguished as belonging to the "highland/lowland [or] north/central/south," as "urban/rural [or] "province/capital" fare, as stereotypically pre-Hispanic/Spanish-influenced or traditional/ indigenous/mestizo food, etc. (Camacho I56; Weismantel I2O, I2O). Despite the ample and diverse set of foods which constitute Ecuadorian cuisine, Ecuador is home to a population afflicted by nutritional deficiencies. Unsurprisingly, these varied diets and their determinants generate differing nutritional conditions (Camacho ${ }_{5} 6$ ). In fact, issues including undernutrition, obesity, and micronutrient deficiency lend themselves to the "deleterious nutritional situation" prescribed by the World Bank in their most recent country study report on Ecuador (Walker et al. xiii).

ETHNIC, SOCIOECONOMIC, \& GEOGRAPHICAL DIVERSITY: SHAPING OF THE ECUADORIAN DIET

Though there is much richness and pride in Ecuador - as expressed through Ecuadorian culture, food, etc. - many among the country's heterogenous society are subjected to inequalities that prohibit the population from sharing "the same general conditions of wellness" (Ortega). Currently, the majority of the Ecuadorian population (approximately seventy-two percent) identifies themselves as mestizo; this social group became dominant in Ecuadorian society upon its rebirth and independence from three hundred years of Spanish colonization in I830 (Ortega). In the Andes in particular, the mestizo people can be characterized by how "white... [they] have become," while the indigenous people "have 'remained' ... [as] shaped by the interaction of relations of power" (Weismantel 38).

Though almost two hundred years have passed since Ecuador's liberation from Spain, the smaller percentage of the republic's population (which can trace its ancestry back to Amerindian or African roots) maintains a lesser, subjugated position in society - like many cultures globally, the shadow of colonization still holds its grip on Ecuador. Because of the history of abuse, discrimination, and stereotyping (based on religion, skin color, language, etc.) that was born during Ecuador's Spanish colonization and which remains in Ecuadorian society today, twenty-seven generations of indigenous peoples and Afro-Ecuadorians have lived in static, impoverished conditions. Consequently, for over five hundred years, these communities have 


\section{"Over the centuries, the different cultural groups across Ecuador have adopted various food habits and diets due to their respective histories and geographical locations."}

experienced limited access to water and land, high levels of food insecurity, and general social discrimination (Ortega). As a result, an "ongoing tension in Ecuadorian society" has been established (Walmsley 45). Currently, ethnicity plays an especially important role in the diet of indigenous and Afro-Ecuadorian peoples; because of their recognition of "the discrimination they face in daily life," these individuals "increasingly express pride in their cultural difference" - particularly in the form of food (Walmsley 45).

Because one's diet, and subsequently, one's nutrition are "mediated by... socioeconomic factors" in addition to "cultural choices," the history behind these determinants are an interesting consideration when looking at current dietary patterns (Camacho I56). Prior to the Spanish colonization of Ecuador, for instance, the native Andean population consumed a diet containing "many of today's basic products" including tomatoes, maize, beans, potatoes, and other tubers; quinoa, squash, and a variety of wild fruits, berries, and other plants were consumed regularly (Camacho 157). Upon the Spaniards' colonization, however, the "Andean diet was modified" by "the transplantation of animals and plants ... and new dietary habits" (Camacho I57; Schlüter 9I). As new grains live., wheat and barley land protein sources such as chickens, pigs, cows, and other livestock, and legumes and vegetables were made available, a "much richer and more varied diet" emerged (Camacho I57; Schlüter 9I).

This was not without consequence, particularly in indigenous communities. Without access to many of the new products, in addition to "colonial socioeconomic institutions" that "[transformed] the landscape and [exploited] native resources and labor," such as plantations and sharecropping systems not all areas of society shared the same "improvements in diet and health" (Camacho I57, I57, I67). The availability of both new foodstuffs and new socioeconomic hierarchies, which were established after the arrival of the Spanish conquerors, also led to a decreased consumption of many traditional foods. All over Latin America, "conquest and cultural colonization resulted in $[. .$. negative cultural stereotypes which clearly influenced the disappearance of traditional [ foods]" and ultimately caused the loss of "staple elements" of the traditional Ecuadorian diet (Schlüter 97). For instance, certain foods were deemed "peasant food," and consequently no longer eaten despite their nutritional density; while all levels of Ecuador's society were necessarily affected by this designation, the impact of this newfound notion of "food prestige" most significantly affected those of poorer socioeconomic standing (i.e., the native, indigenous population). Though many of these traditional products have been "rediscovered" and reintroduced into the Ecuadorian diet - primarily in an attempt to reduce the country's poverty levels and increase its nutritional outcomes - many have not been reestablished until somewhat recently (Schlüter 92).

A classic example of the issue of food prestige can be seen in the case of quinoa. This nutritious, protein-rich pseudocereal was long disregarded as "animal feed," and not reintroduced into the Ecuadorian diet until its "rediscovery" in the late I990s and early 2000 s (Ortega et al.). Because quinoa contains all nine essential amino acids, it functions as a nutritious, vegetarian protein source - which is particularly beneficial for those communities that do not readily have access to animal proteins. For thousands of years, the native inhabitants of Ecuador's Sierra cultivated and consumed quinoa, until the Spanish conquest of the country; this marked a four-hundred year decline in quinoa production, as the seed was deemed "food for Indians" and later "only fit for animal consumption" (Dobkin; Ortega et al). Ironically and rather unfortunately, the disappearance of this nutritious protein and carbohydrate source was coupled with an increase in malnutrition in the population whose ancestors had originally considered quinoa a dietary staple - the indigenous peoples (Dobkin). It was not until European agricultural researchers "rediscovered" quinoa that it was once again reintroduced into the diet and farming practices of Andean communities (Ortega et al.). Since then, efforts to provide opportunities for the growth of this pseudo-grain have helped improve the lives of farmers and communities in the Andes, "where poverty rates are historically high and nutrition miserably low" (Dobkin). Ultimately, quinoa's rediscovery has led to in- 
i creased nutritional and socioeconomic outcomes in the Sierra region, as the seed once again became a source of both vital nutrients and income for many in need of its dietary benefits (viz. the indigenous population).

Today in the rural portions of the Sierra - and primarily, among the indigenous communities who have resided there for generations - "maize, quinoa, and tubers remain central crops" as they have for centuries (despite quinoa's lengthy absence); in effect, the "persistence of a diet largely based on native crops" has considerably shaped the Andean diet (Camacho I57, I58). For the "traditional peasant," a standard diet is characterized by a large presence of starches and carbohydrates (e.g., "cereals, tubers, [and] legumes" such as barley, potatoes, and fava beans). In fact, the importance of these food types is incorporated not only "into the structure of meals, but [also] into the structure of the landscape" and culture (Camacho I58, I58; Weismantel II7). Grains and starches traditionally held "cultural and symbolic position in the Andean cosmological vision," and remain "synonymous with food" because of their nutritional properties that provide "a feeling of satiety and strength" (Codesal; Camacho I58, I58-159). For those of lower socioeconomic standing, they provide an important source of energy; in fact, for the region's poor, other nourishing and satiating foodstuffs - viz. proteins sources such as meat, eggs, and dairy products - are only available according to a given community or family's "economic opportunities" (Camacho I58). Because of this, in the Sierra and particularly in rural, low-class and indigenous villages, nutritional needs are often not met.

However, while Ecuadorians living in the Sierra consume these traditional foods for their affordability, convenience, and cultural significance, there is a marked tension between traditional culinary choices and more modern, mestizo foods. Here, one can once again find traces of the issue of food prestige - despite the fact that similar dietary trends can be observed across Ecuador. In effect, surveys indicate that "rice and oats, wheat-derived products, potatoes and manioc, sugar, lard and oil" and "plantains [and bananas]" appear to have a major role in the Ecuadorian diet (Camacho I58). But, because of the tie between food and social identity, perceptions of foods can be seen to impact the dietary choices of all class levels. For instance, some children in indigenous communities - such as those which live in Cotacachi, a city in the Sierra that is host to the highest density of indigenous peoples of any city in the country - often prefer "high status mestizo foods" (such as fast foods, foods prepared using more urban approaches, etc.) over their own traditional, rural fare (Camacho I59). This social phenomenon is seen by some anthropologists as a reaction to the children's "desire to become mestizo and to assimilate into the master culture (Camacho I59). Ultimately, it conveys the strength of the "language of food" in Ecuadorian culture and the power of the notion of food prestige (Camacho I59).

A similar phenomenon can be seen in the middle- and upper-class, albeit in a more elitist manner. While certain indigenous peoples choose to align themselves with mestizo culture, many other Ecuadorians who are well-off (and especially those in urban centers) conversely wish to separate themselves from their lower-class (and indigenous) compatriots. For instance, in Quito Ecuador's capital, which is nestled in the highlands among the mountains and volcanos of the Sierra - a tension exists between "competing cuisines" (including that between traditional vs. fast foods); ultimately, a "complex hierarchy of cuisines" exposes cultural schisms "between social roles... old and young, man and woman, [and] rich and poor" (Weismantel I2I, I22, I2I).

As cultural anthropologist Dr. Weismantel observes, many in Quito and other urban centers have an often conflicting desire to not only uphold traditional Ecuadorian cuisine particularly in reaction to the fear of Western, specifically American, encroachment on Ecuador's “integrity as a nation... and unique [food] culture" (e.g., through the establishment of fast food restaurants and the importation of canned goods, snack foods, soft drinks, etc.) - but also

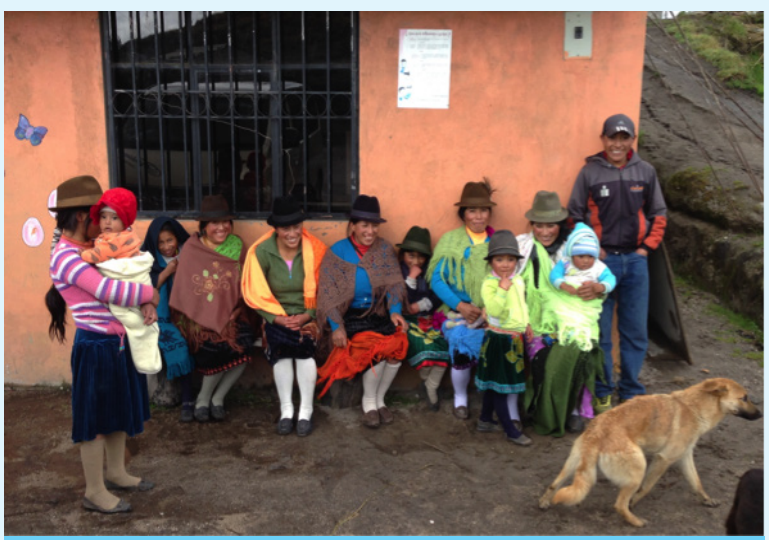

FIGURE 2: VISUALIZING THE STUNTING PRESENT IN TINGO, ECUADOR (COURTESY OF LINDSAY STONE) 
both differentiate their diet from that of the traditional cuisine and separate themselves from the people it represents (Weismantel I22). Consequently, Ecuador's traditional dishes - i.e., "platos tipicos" - can represent both the country's cultural heritage, and "the poor, the ignorant, and the nonwhite: people with whom the elite, for the most part, do not wish to identify" (Weismantel I22). Because "race remains a defining, if often unspoken, feature of social relations" in Ecuador, one's attempt to identify oneself within their social construct is often affected by societal and cultural perceptions of foods. Consequently, many Ecuadorians struggle to "[emphasize] their country's cultural heritage" while maintaining a discourse of food prestige (Walmsley 46).

However, the issue of food prestige can go beyond "traditional" foods and be applied to any food item deemed not prestigious enough for higher-class consumption. Take baby carrots, for example: from an ethnocentric, American perspective, one could describe this colorful food item as a nutritious source of many vitamins, minerals, and fiber that is considered delicious by many adults and children alike. However, Ecuadorian-born Dr. Marleen Haboud explains how, in Quito, baby carrots are deemed "animal food," just as quinoa was for centuries (Ortega et al.). From personal experience, she recalls how this food item is not considered an appropriate snack for children - she was, in fact, reproached by another parent upon giving baby carrots to her daughter as a snack to take to school - even though baby carrots are a healthy option, unlike many of the processed snack (and often junk) foods that many parents choose to give their kids instead (Ortega et al.). Because carrots are not viewed as a "high-class" option (as processed snack food has come to signify, at times) and thus do not fit in with the concept of food prestige that many try to uphold, many well-off Ecuadorians disdain their consumption.

Ultimately, as a result of socioeconomic influences and Ecuador's history of colonization, repression, and classstratification, food in Ecuadorian society can be seen to function in a semiotic manner, endowed with meaning according to cultural signification and its dissimilarity from other foods. Accordingly, food and diet necessarily play a significant role in the establishment and maintenance of one's social and cultural identity. However, the significance of the "alimentary language" - which, though not unique to Ecuadorian society, is particularly noteworthy - can also lend itself to the possibility of an amplification and distortion of "rules of exclusion," "alimentary ta- boos," and "rules of association, as can be seen in the case of food prestige" (Weismantel I24).

Despite the importance of culture and socioeconomics, "ecological [factors] ... [and] local environmental conditions" also contribute to the shaping of the Ecuadorian diet (Camacho 156). Amidst the various considerations that form a population's food choices, both geography and socioeconomics share similarly significant roles, and can, in fact, go so far as to build a "relationship between race and place" (Walmsley 45). Such is the case in Ecuador, where "race is understood in terms of place" and "[these] intersecting social constructions" produce a sense of identity - thus, "regional cuisines... often become representative of local [Afro-Ecuadorian], indigenous, or mestizo culture" (Walmsley 43).

Though nationally traditional Ecuadorian foods are characterized by their "substantial, solid" nature, whereby meals are cooked via "a rather limited repertoire of techniques, condiments, and vegetables" and are often "starchy," a substantial amount of diversity can be found among regional cuisines (Weismantel I2I, I2O-I2I, I2I). Containing ingredients such as goat, beef, chicken, rice, potatoes, onions, and eggs, Ecuador's "platos tipicos" often vary by geographic area; for instance, the bland, potato dominated cuisine of the highlands is entirely distinctive from the spicy, rice focused meals served in the coastal region (Weismantel I22). These regional differences can interact with discourses of socioeconomics and culture and once again lend themselves to an alimentary language and the issue of food prestige - which further shapes "the relationship between race, place and cuisine in Ecuador" (Walmsley 46). Ultimately, a "racial topography" can be mapped upon Ecuador's natural geography, which creates "racial identities that are spatially located and materially experienced through diverse culinary processes" - and, as a result, establishes a "racial/spatial order" (Walmsley 49, $46,49)$. In this way, foods, tastes, smells, and cuisines develop regional and cultural markers that are identifiable as belonging to a "designated cultural and geographical setting” (Walmsley 50).

Aside from its "racial/spatial" element, geography also has its unique impact on the Ecuadorian diet. Between the north and south coastal plains, the mountainous Andean highlands, and the Amazon basin, Ecuador is home to "considerable diversity of climate, ecosystems" and elevations - the latter of which can range from sea level to more 


\section{i "[The] often-harsh environment of the Sierra...necessarily shapes the diet of the peoples living there..."}

than twenty-thousand feet above sea level (Walmsley 46). The country's eco-geographical variations necessarily lend themselves to a diversity of food products in diets, which are associated with different regions. For instance, production zones and land use are ultimately established according to "[variations] in topography, altitude, and climate" (Weismantel 39). Though the transportation of food is not nonexistent, such that "foodstuffs do not, of course, remain within their places of origin," many specific ingredients are stereotypic to a given region (Walmsley 47). It is commonly held, for example, that "potatoes and cereals belong to the high Andean mountainsides," while "seafood... [and] tropical fruits, with their glowing colors and cloying fragrances" evoke the cuisine of coastal lowlands; these associations frequently stem from a food item's ability to grow and thrive in a region's ecogeographic landscape (Walmsley 46-47, 47).

Much of the Ecuadorian Sierra, for instance, can be characterized by "high-altitude mountain slopes," "wind [that] blows cold," and "sun [that] beats down hard on the bare land" (Walmsley 47). Topography, soil quality, and water access in this region can all affect agricultural production, and thus its populations' diets and agricultural opportunities (Camacho I60-I6I). Communities settled in lower altitudes in the Sierra, for example, have the region's "highest levels of agrobiodiversity given the more benign climatic conditions," but are faced with issues relating to lower quality, drier soils and proximity to urban centers (Camacho I6I). Moreover, in the more rural highland areas, "the ruggedness of the terrain, the lack of roads, and the extremely dispersed settlement pattern" further intensify the severity of the landscape (Weismantel 39).

This often-harsh environment of the Sierra, particularly in rural areas, necessarily shapes the diet of the peoples living there, as it can limit options for crop growth and livestock husbandry, decrease opportunities for trade, etc. The rural, poor, indigenous community of Zambagua, for example, lies high up in the Sierra "above the zone of maize cultivation"; accordingly, they are unable to use this crop as a dietary staple and carbohydrate source and instead rely on potatoes as one of the three main crops (Weismantel II8). The predominance of potatoes in rural Andean soci- eties is not uncommon; in fact, some have observed that "the potato is renowned as the mainstay of the indigenous Andean diet" (Weismantel 92). Because potatoes, tubers, and other starches grow well in the Sierra's higher zones - potatoes, in particular, are observed to "grow bigger and better in this zone" - these foods' prevalence "is written... into the structure of meals" (Camacho I6I; Weismantel II8). Patterns such as this are prevalent across Ecuador, as regional diets are ultimately shaped by geography and ecology - such that "highland/lowland," "north/central/ south," "urban/rural." (Weismantel I20).

\section{EXTERNAL FACTORS: THE IMPACT OF THE U.S.}

\section{ON THE ECUADORIAN DIET}

Though many internal factors necessarily shape the dietary choices of Ecuadorians, the country's diet does not exist without external influences (as has been previously mentioned). While there has been, historically, the importation of new foods and eating habits, the mixing of native and non-local diets and cuisines, etc. (e.g., due to the Spanish conquest of Ecuador), the effect of other cultures on the Ecuadorian diet can also be observed today; this is specifically the case with more industrialized countries such as the United States as a result of globalization, urbanization, and an increased exposure to other cultures. Most notably, Ecuador's diet and nutritional status has been negatively impacted by "rapid urbanization and the adoption of Western diets high in refined carbohydrates, saturated fats and sugars". This has permitted the availability of food types which can lend themselves to obesity and improper nutrient intake along with other health problems, such as diabetes, that have been correlated with the consumption of highly processed, high fat, high sugar, and/or high salt foods (World Bank).

Across Latin America, for instance, "the influence of 'junk food' from the United States" functions as an example of "cultural homogenization" - a phenomenon which often emphasizes "the features of industrialized countries at the expense of local traditions" (Schlüter 90). Accordingly, industrialized foods may become exalted and even function as an indicator of food prestige - though it is also possible 
for the opposite to occur. In fact, not everyone is as enthralled with American fast food items in Ecuador (though it is often very popular, especially with the youth); many parents, for instance, feel that "such meals are signposts on the road to perdition," while others view "the cultural invasion of the north" as an encroachment on Ecuador's unique gastronomical heritage (Weismantel I22). The influence of the industrialized countries can also be seen through instances of "cross-breeding" between non-local and local foods, whereby foreign tastes are "[adapted] to local tastes” (Schlüter 90). For example, while McDonald's has been noted to generally have a "disinterest in modifying their menu to accommodate local tastes," their offerings in Ecuador include a "McFiesta" - a "variety burger" topped with guacamole, that is not offered in the U.S. (Oldakowski 46,42 ). Burger King, on the other hand, can be seen to "[demonstrate] noticeable deviation from their American Menu" as they attempt to adapt to the local culture, by including menu items such as "a chicken sandwich with Ecuadorian condiments named Pollo Frito" (Oldakowski 43, 44).

However, the effect of industrialized countries on Ecuadorians is not only limited to their diet, but also their dietary practices. For instance, the marketing campaigns of many infant formula companies in developing countries, such as Ecuador, inevitably led to the decrease in breastfeeding - and particularly exclusive breastfeeding - practices. Though breastfeeding is popular among indigenous communities - around seventy-seven percent of indigenous women breastfeed their infants because it is cost effective (i.e., free), convenient, and deemed healthymany others "[resist] exclusive breast-feeding and [instead partake in] inappropriate complementary feeding" practices which ultimately lead to increased infant

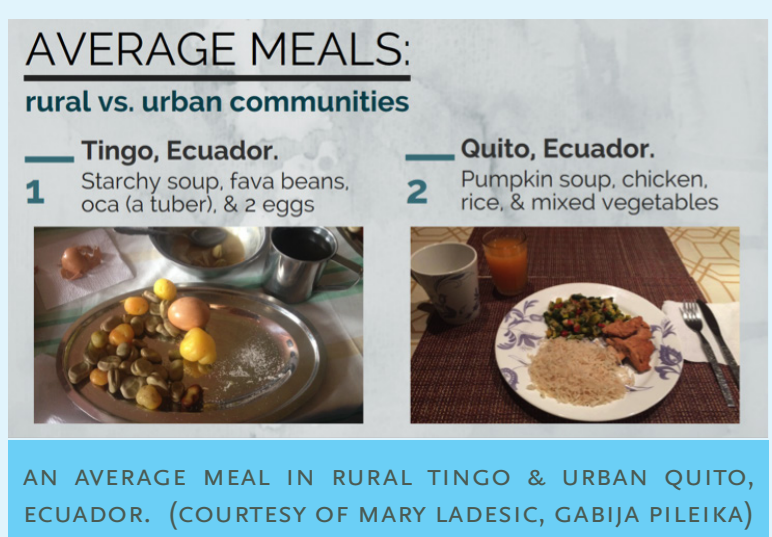

mortality (Ortega; Walker et al. xvii, 4). While studies have shown that, when administered correctly, infant formula can be healthful, safe, and nutritious - though still suboptimal to breastmilk - ultimately "manufacturers [failed] to gear the product to a developing society". Thus, by not considering the "environment of poverty, illiteracy, inadequate sanitation, unhealthy water and limited health services" that afflicts many in developing countries (including Ecuador), infant formula companies failed to provide a truly beneficial and viable option - for, ultimately, "as more women [shifted] from breastfeeding to infant formula feeding... more infants [died]" (Zelman 708; Post qtd. in Gilly et al. 23; Zelman 708).

Because diets do not exist in isolation from outside influences, and are not exempt from the importation of new foods and habits, etc., it can be said that the Ecuadorian diet was shaped - even to this day - by international (and particularly more industrialized) countries, such as the United States. While this is not without impact to the integrity of national traditions and the health of the population, it necessarily occurs given the globalized nature of the world today. While some aspects of cultural homogenization, cross-breeding, and international advertisement and marketing may have a null or even positive effect on Ecuador's diet, many (such as the importation of fast-food and junk food, marketing which promoted infant formula, etc.) can be seen to have adverse effects on the country's health, wellbeing, and malnutrition.

\section{NATIONAL PATTERNS OF MALNUTRITION}

Though the origin of much of the country's social inequality can be traced back to the period of the Spanish conquest and colonization of Ecuador, history, and socioeconomics only tell a part of the story. As a result of geographical, cultural, social, and other factors, Ecuador's four regions - and the ethnic groups within them - have necessarily established very different levels of malnutrition and malnutrition-related conditions. For instance, the World Bank suggests that the patterns of malnutrition observed across Ecuador have been exacerbated by "limited access to nutritious food," "poor infant feeding practices," and "high disease burden" -since malnutrition and disease exist within a vicious cycle -among different populations (and at different levels) (World Bank). Moreover, because Ecuador has failed to "target relevant populations with the right interventions," this Latin American country is among several in the region "which report persistently 
high rates of childhood nutritional deficiency" (Walker et al. xiii, xiii). Thus, "in this setting, the deleterious nutritional situation" has arisen (Walker et al. xiii).

While levels of the total percentage of under-five Ecuadorians who are overweight or obese is around nine percent, it is indubitable that chronic malnutrition (which affects around twenty-five percent of the under-five-yearold population) has a greater effect on the Ecuadorian population - and particularly those in the highland region (Freire et al.). Chronic malnutrition is manifested as stunting. When looking at a region's stunting rates in relation to the national stunting levels, the Sierra is home to sixty and sixty-three percent of the country's moderately and severely stunted under-five year olds. Among this stunted population, fifteen to twenty percent live in or around urban centers in the Sierra (such as Quito), as opposed to the remaining forty to fifty percent who live in rural highland areas. In the lowland coastal region, the moderately and severely underweight individuals account for thirty-four and twenty-nine percent of Ecuador's stunted under-five population, respectively (Walker et al. I2).

In addition to this regional data, it is also interesting to look at the levels of stunting in a given area relative to its population. For instance, though Sierra is known for its high levels of stunting per capita, the Amazonia's rates are almost as high - as the World Bank states, the likelihood of being moderately stunted in the highland population is roughly thirty-two percent, and approximately twentythree percent in the lowland, Amazonia population (Walker et al. I2). In contrast, the Costa has significantly fewer levels of stunting than the other two regions, such that only around sixteen percent of its population is predicted to experience stunting in any form (Walker et al. I5). Ultimately this data indicates that the populace of the Sierra experiences not only much higher levels of stunting relative to the country's population - and, by association, malnutrition - but also larger disparities between rural and urban conditions than the other regions. Urban-rural discrepancies in this area cause acute differences in the prevalence of malnutrition, as those in rural communities often endure more extreme environmental conditions, experience more energy-demanding lifestyles, and consume less nutrient-rich diets; such inconsistencies can be seen in the average meal. This pattern of higher levels of malnutrition in rural vs. urban areas is not unique to Ecuador, and can also be found in other Latin American countries.

\section{CONCLUSION}

Though eating is a daily activity whose significance is not necessarily given much thought, one can obtain valuable insights into an individual's cultural and social settings, economic conditions, cultural heritage, and physiological well-being by observing the cuisines, foods, and meals that they consume. A variety of factors unique to each individual or population group can impact how it is prepared, what one chooses (or does not choose) to eat, how it is perceived culturally or socially, what parameters dictate why it is eaten, and in what manner it is eaten. Consequently, analyzing the nutritional status - which is above all dependent upon the foods consumed, in addition to other secondary factors - in a country, region, or single community is an important method of understanding the many aspects of the population's socioeconomic circumstances, environmental settings, and, particularly, their overall physical and mental health.

When looking at Ecuador, one can identify a variety of conditions which lend themselves to different food consumption patterns - and thus ultimately the nutritional state of the individuals who prescribe to them. Among these circumstances, several in particular remain central to the development of Ecuador's current nutritional status: the country's ongoing urbanization, the influence of industrialized nations on the traditional diet, the existence of a nutritional transition, the implications of Ecuador's colonial history, the presence of distinct ethnic groups, and other key factors can all be attributed to the high (although, in some cases, improving) levels of malnutrition. In particular, Sierra is noteworthy as it is a geographically intense region within a developing country. Moreover, the large percentage of indigenous peoples - who have a history of exploitation which continues today - living in the Sierra are exposed to a variety of dietary, environmental, and socioeconomic factors which promote malnourishment. Accordingly, it is not surprising to find that this highland region experiences the highest levels of chronic malnutrition in the country as is manifested through the presence of stunting. 


\section{REFERENCES}

Camacho, Juana. "Good to Eat, Good to Think: Food, Culture and Biodiversity in Cotacachi." Development with Identity: Community, Culture and Sustainability in the Andes. Ed. Robert E. Rhoades. Wallingford, UK: CABI Pub., 2006. I56-70. Google Books. Web. 2016.

Codesal, Diana Mata. "Eating Abroad, Remembering (At) Home. Three Foodscapes of Ecuadorian Migration in New York, London and Santander." Anthropology of Food 7 (20IO).

Dobkin, Leah. "Quinoa Comeback." Americas 60.5 (2008): 28-37. ProQuest. Web. Io Jan. $201 \%$.

Freire, W. B., K. M. Silva-Jaramillo, M. J. RamirezLuzuriaga, P. Belmont, and W. F. Waters. "The Double Burden of Undernutrition and Excess Body Weight in Ecuador." American Journal of Clinical Nutrition I00.6 (2014): 1636S-I643S. PubMed. Web. Feb. 2016.

Gilly, Mary C., and John L. Graham. "A Macroeconomic Study of the Effects of Promotion On the Consumption of Infant Formula In Developing Countries." Journal of Macromarketing 8.I (I988): 2I-3I.

Ladesic, Mary. “An Average Meal in Quito, Ecuador.” 20I7. JPEG file.

Oldakowski, Ray, and John McEwen. "The Diffusion of American Fast Food to Ecuador." Material Culture (2010): 28-49.

Ortega, Fernando, Marleen Haboud. Personal Interview. 24 October 2016.

Ortega, Fernando. "Health and Inequality in Ecuador." 24 October 20I6, Boston College, Chestnut Hill, MA. Guest Lecture.

Pileika, Gabija. "An Average Meal in Tingo, Ecuador." 20I4. JPEG file.

Schlüter, Regina G. "Promoting Regional Cuisine as Intangible Cultural Heritage in Latin America." Food and The Tourism Experience (2012): 89-99.
Stone, Lindsay. "Growth Curve (Height/Age) for UnderFive Male and Female Children in Tingo, Ecuador." 20I4. JPEG file.

Walker, Ian, and Alessandra Marini. Nutritional Failure in Ecuador: Causes, Consequences, and Solutions. Washington, D.C.: World Bank, 2007. Web. 2016.

Walmsley, Emily. "Race, Place and Taste: Making Identities Through Sensory Experience in Ecuador." Etnofoor, vol. 18, no. I, 2005, pp. 43-6o

Weismantel, Mary J. Food, Gender, And Poverty in The Ecuadorian Andes. Philadelphia: U of Pennsylvania Press, I988. Print.

Zelman, Nancy Ellen. "The Nestle Infant Formula Controversy: Restricting the Marketing Practices of Multinational Corporations in the Third World." Transnational Lawyer 3.2 (I990): 697-758. 